\title{
Genetic Analysis of Familial Isolated \\ Growth Hormone Deficiency Type I
}

\author{
J. A. Phillips III, J. S. Parks, B. L. Hjelle, J. E. Herd, L. P. Plotnick, \\ C. J. Migeon, and P. H. Seeburg, Department of Pediatrics, Johns Hopkins \\ University School of Medicine, Baltimore, Maryland 21205; Department of \\ Pediatrics, University of Pennsylvania School of Medicine, Philadelphia, \\ Pennsylvania 19104; Department of Molecular Biology, Genentech, Inc., \\ South San Francisco, California 94080
}

A B S T R A C T Nuclear DNA from individuals belonging to nine different families in which two sibs were affected with isolated growth hormone deficiency type I were studied by restriction endonuclease analysis. By using ${ }^{32} \mathrm{P}$-labeled human growth hormone or the homologous human chorionic somatomammotropin complementary DNA (cDNA) sequences as a probe, the growth hormone genes of affected individuals from all families yielded normal restriction patterns. Polymorphic restriction endonuclease sites (HincII and $M s p I$ ), which are closely linked to the structural gene for growth hormone on chromosome 17, were used as markers in linkage analysis of DNA of family members. Of the nine affected sib pairs two were concordant, three were possibly concordant, and four were discordant for both linked markers. Since only concordant sib pairs would have inherited the same growth hormone alleles, further studies to identify mutations of the growth hormone genes should be limited to this subgroup. It is unlikely that the discordance observed in four of the sib pairs is due to recombination, because the polymorphic HincII site is only 116 base-pairs from the -26 codon of the growth hormone gene. Thus, in at least four of the nine families, the mutation responsible for isolated growth hormone deficiency is not within or near the structural gene for growth hormone on chromosome 17.

\section{INTRODUCTION}

Human growth hormone $(\mathrm{hGH})^{1}$ and human chorionic somatomammotropin (hCS) are closely related poly-

\footnotetext{
A preliminary report of these studies was presented at the meeting of the American Society of Human Genetics, Dallas, TX, October 1981 and appeared in abstract form in 1981 . Am. J. Hum. Genet. 33: 52a.

Received for publication 1 March 1982 and in revised form 30 April 1982.

${ }_{1}$ Abbreviations used in this paper: bp, base-pairs; GH-L, growth hormonelike sequences; hCS, human chorionic so-
}

peptide hormones with $92 \%$ homology between their mRNA coding sequences $(1,2)$. Following digestion with EcoRI, the hGH and hCS genes are contained in 2.6- and 2.8-kilobase (kb) fragments of genomic DNA, respectively, while a third uncharacterized fragment $(9.5 \mathrm{~kb})$ contains homologous or "GH-like" (GH-L) sequences $(2,3)$. Although all of these components of the hGH gene cluster are located on the long arm of chromosome 17, the arrangement of the components relative to each other is not known $(3,4)$. Studies of the nucleotide sequences of isolated genomic clones suggest there are at least two types of $\mathrm{hGH}$ and two types of hCS genes $(2,5,6)$. One locus of hGH (hGHN) encodes the known protein while another (hGH-V) encodes a protein with 14 amino acid differences from the normal, mature GH $(7,8)$.

Human GH is synthesized and released by anterior pituitary cells under hypothalamic influence. Lack of hGH production causes metabolic alterations and growth failure (9). Most cases of hGH deficiency are idiopathic, but there are several single gene disorders that are associated with an isolated deficiency or absence of hGH (10). One form of familial isolated growth hormone deficiency (IGHD) is inherited as an autosomal dominant. Another form is X-linked recessive and is associated with hypogammaglobulinemia (11). Finally, there are two forms (types I and IA) that have an autosomal recessive mode of inheritance. In type I, low but detectable levels of immunoassayable hGH may occur, but in type IA hGH secretion is absent due to the deletion of the hGH-N gene $(7,10,12)$.

One can postulate two explanations for the reduced hGH levels seen in IGHD type I (IGHD I): one involves mutations in or near the hGH genes, while the other

matomammotropin, hGH, human growth hormone: $\mathrm{N}$, normal; V, variant; IGHD, isolated growth hormone deficiency; kb, kilobase(s). 
involves mutations of distant loci that affect the embryological development, cellular composition, or neuroendocrine regulation of the anterior pituitary. In analogy to disorders of hemoglobin, a wide variety of hGH gene defects could cause an altered hGH polypeptide that would have decreased immunological and biological potency or a deficient amount of structurally normal hGH peptide (13). Alternatively, IGHD I could be associated with normal hGH genes that are rendered nonfunctional by mutations of other "regulatory" loci that control functions of the hypothalamus and/or anterior pituitary cells (10-12).

In contrast to IGHD IA, preliminary studies in our laboratories on DNA from individuals with IGHD I indicated that the hGH-N gene sequences were grossly normal. To determine if the hGH-N genes or their flanking sequences were subtly altered in IGHD I, we then used linkage analysis rather than DNA sequencing. We studied nine families with two affected sibs to determine if both affected children had inherited the same hGH-N gene from each parent. If the defect causing IGHD I were within or near the structural gene for growth hormone we should have found that each of the nine affected sib pairs was concordant for the hGH-N alleles inherited. We found that of the nine affected sib pairs studied, two pairs were concordant, three pairs were possibly concordant, and four pairs were discordant for the markers and, hence, the hGH$\mathbf{N}$ alleles inherited. Since four of the nine sib pairs were discordant, we believe a large fraction of cases of IGHD I are due to defects that occur elsewhere in the genome. These results demonstrate the usefulness of linkage analysis in confirming that a mutation causing disease is within a specific gene before DNA sequencing of that gene.

\section{METHODS}

Clinical material. We studied DNA from members of nine families (A-I) whose pedigrees are shown in Fig. 4. All nine families had parents of normal height and two sibs affected with IGHD I. Our criteria for IGHD I include $(a)$ no demonstrable anatomic cause for IGHD, $(b)$ stature $>2$ SD below mean for age and sex, (c) significantly delayed bone age, $(d)$ peak GH levels $<7 \mathrm{ng} / \mathrm{ml}$ after standard pharmacologic stimulation, $(e)$ deficient growth velocity that responded to parenteral hGH, $(f)$ normal thyroid function, (g) spontaneous pubertal changes at an appropriate bone age, and $(h)$ no known immunodeficiency or history of recurrent infection in cases from pedigrees having only affected males. Controls were unrelated individuals of normal stature who had no endocrine disease.

Nuclear DNA preparation. High molecular weight DNA was prepared as described (14) from peripheral blood (10$30 \mathrm{ml}$ ) obtained from controls and all individuals shown in the pedigrees in Fig. 4 except the parents in family E, who were deceased.

Probe preparation. The recombinant plasmid chGH 800/ pBR 322 contains nearly full-length complementary DNA
(cDNA) to hGH mRNA (15). The 800-base pair (bp) hGH cDNA insert was isolated from pBR 322 DNA by HindIII digestion, followed by electrophoresis and recovery from agarose gels (16). The purified $800-\mathrm{bp}$ DNA fragment was labeled to a specific activity of $\sim 10^{8} \mathrm{cpm} / \mu \mathrm{g}$ using $\left[\alpha-{ }^{32} \mathrm{P}\right] \mathrm{dATP}$ and $\left[\alpha-{ }^{32} \mathrm{P}\right]$ deoxycytidine triphosphate $([\alpha-$ ${ }^{32}$ P]dCTP) by "nick translation" with Escherichia coli DNA polymerase I (17). This probe was used in restriction analysis of DNA samples from all families except $E$ and $I$. For samples from families $E$ and $I$, the probe used was derived from the recombinant plasmid chCS 550/pMB9 that contains cDNA to hCS mRNA (18). Experiments involving recombinant DNA were conducted at P2-EK2 containment in accordance with the National Institutes of Health guidelines.

Restriction endonuclease analysis. Aliquots of nuclear DNA prepared from individual family members and controls were digested to completion with various restriction endonucleases under conditions recommended by the commercial supplier (Bethesda Research Laboratories, Rockville, MD). Digested DNA and appropriate DNA size markers were subjected to electrophoresis in $0.8-1.25 \%$ (wt/vol) agarose gels. In some cases, genomic DNA fragments of a specific size were isolated from an agarose gel, digested with a second restriction endonuclease, and fractionated on a second agarose gel (19). The DNA fragments were then transferred to nitrocellulose filters and hybridized with the hGH or hCS probe. The filters were then washed and autoradiographed $(4,20,21)$.

\section{RESULTS}

Polymorphic restriction sites identified. Using HincII, MspI, and BglII we found five common polymorphic restriction sites that occur adjacent to or within components of the hGH gene clusters of the families studied as well as controls. As shown in Figs. 1 and 2 the fragments resulting from these polymorphic restriction sites are $6.7 / 4.5 \mathrm{~kb}$ (HincII), 4.3/3.6 kb or $3.9 / 3.3 \mathrm{~kb}$ (MspI), and $13 / 10.5 \mathrm{~kb}$ or $8.1 / 3.0 \mathrm{~kb}$ (BglII) in size. The frequencies in controls of these normal polymorphisms were HincII $6.7 / 4.5 \mathrm{~kb} .68 / .32$ (111 chromosomes), MspI 4.3/3.6 kb .44/.56, 3.9/3.3 kb .41/.59 (54 chromosomes), and BglII 13/10.5 kb $.30 / .70,8.1 / 3.0 \mathrm{~kb}$ $.41 / .59$ (109 chromosomes).

Partial digestion of DNA samples as an explanation for variations in fragment size was excluded by obtaining constant patterns after digestion with 1,3 , or $5 \mathrm{U}$ of restriction enzyme/ $\mathrm{g}$ DNA. Also, prolonged exposure of films did not show any additional differences in patterns not seen on shorter exposure. Finally, in all families studied the segregation patterns of polymorphic fragments agreed with Mendelian inheritance.

Distances from $h G H-N$. Since the restriction map of the hGH/hCS complex is only partially known, the physical distance between most of the polymorphic restriction sites and the hGH-N gene could not be easily determined. The approach used was to show that two of the five polymorphic restriction sites are present in a large restriction fragment that also contains the 


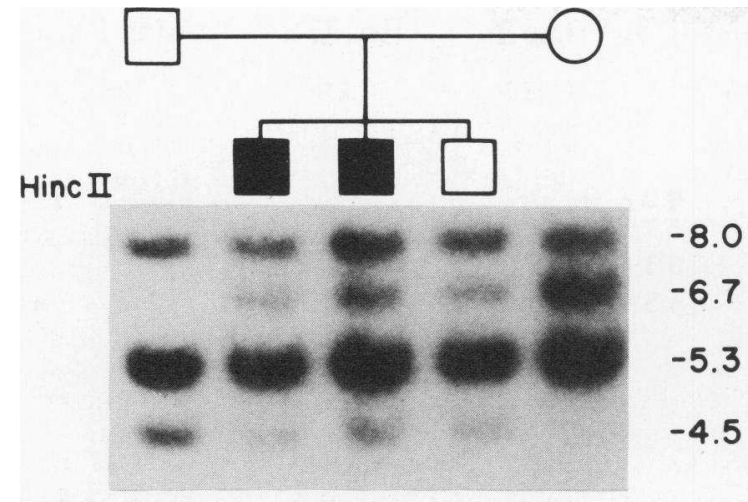

MspI

BglII
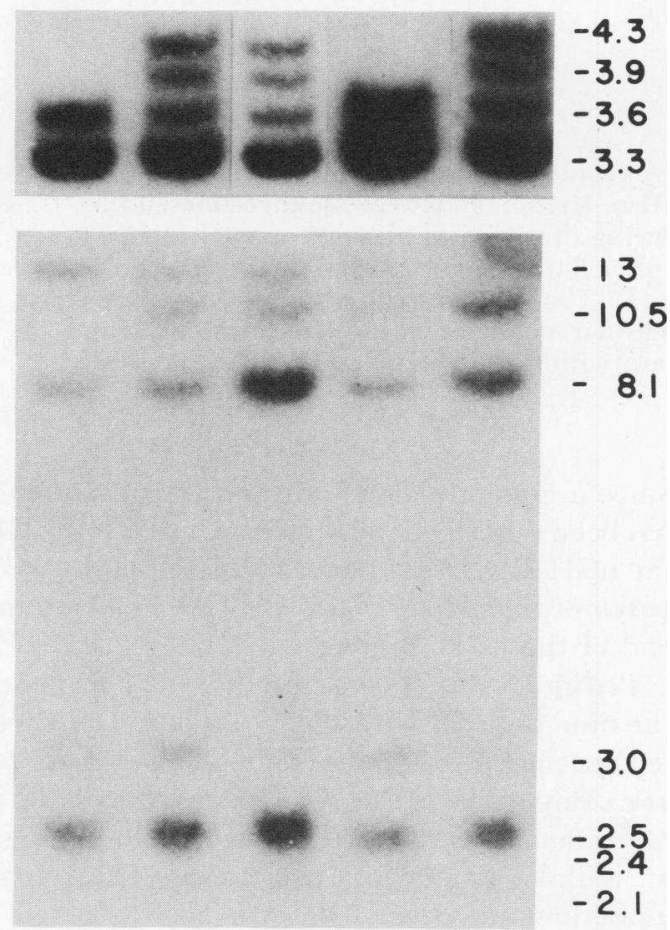

Figure 1 Autoradiogram patterns of DNA from family C after digestion with HincII (top), MspI (middle), or BglII (bottom) restriction endonuclease and hybridization with hGH probe. Fragment sizes in kilobases are on the right (note the $M s p I$ fragments $<3.3 \mathrm{~kb}$ are not shown).

hGH-N gene. Since all the components of the hGH/ hCS gene complex are contained in DNA fragments of 26,23 , and $16 \mathrm{~kb}$ following digestion with HindIII, our first step was to digest genomic DNA from a control with HindIII and isolate the 26-, 23-, and 16-kb hybridizing fragments $(7,19)$. The HindIII recognition sites are known to flank the EcoRI sites within these large fragments (7). Next, EcoRI digestion of the isolated 26-kb HindIII-generated fragment " 26 " (Fig. 3) showed that it contains only the 9.5-kb GH-L and

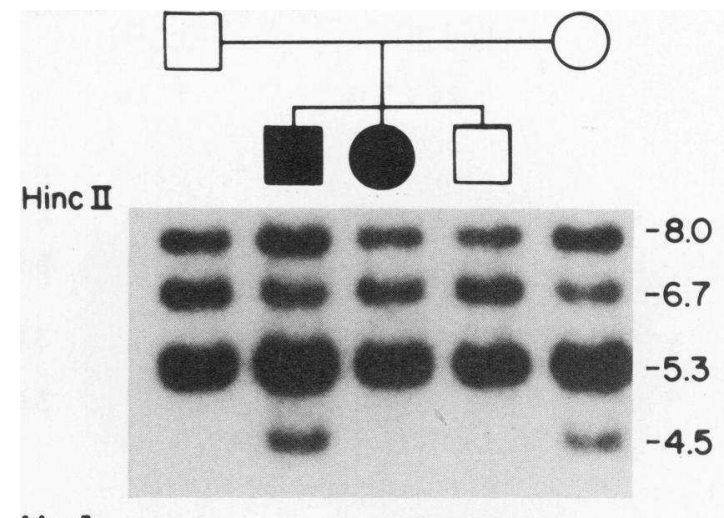

MspI

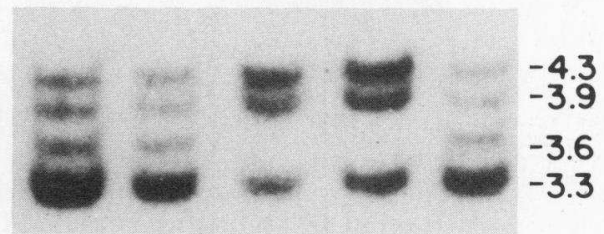

Bgl II

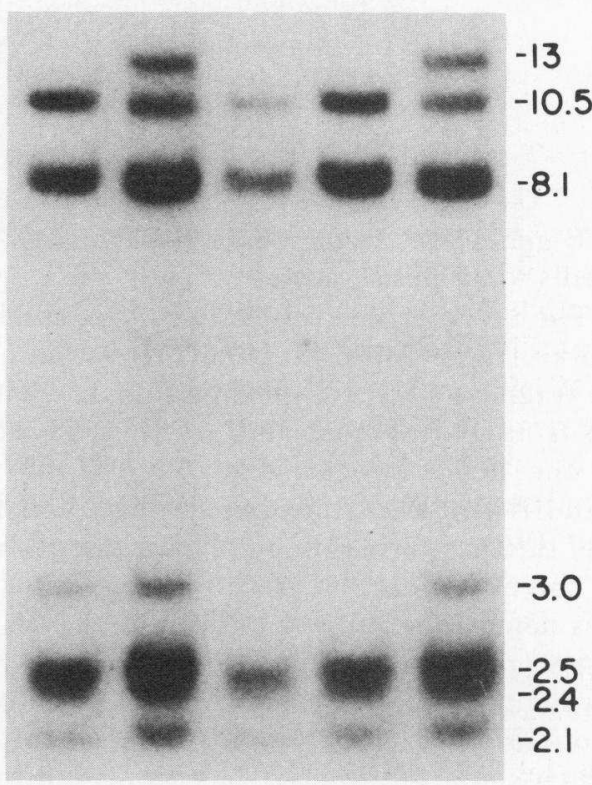

FIGURE 2 Autoradiogram patterns of DNA from family $\mathrm{H}$ after digestion with HincII (top), MspI (middle), or BglII (bottom) restriction endonuclease and hybridization with hGH probe. Fragment sizes in kilobases are on the right (note the $M s p I$ fragments $<3.3 \mathrm{~kb}$ are not shown).

the 2.6-kb hGH (hGH-N and/or hGH-V) fragments. BamHI digestion of " 26 " demonstrated the presence of the $3.8-\mathrm{kb}$ fragment containing the hGH-N gene and an $8.5-\mathrm{kb}$ GH-L fragment. The 1.2-kb fragment, which would be expected from the hGH-V gene, was not present (7). Thus, the isolated $26-\mathrm{kb}$ fragment contains the GH-L and hGH-N genes (Fig. 3). Similar procedures were used to show that the hGH-V and 


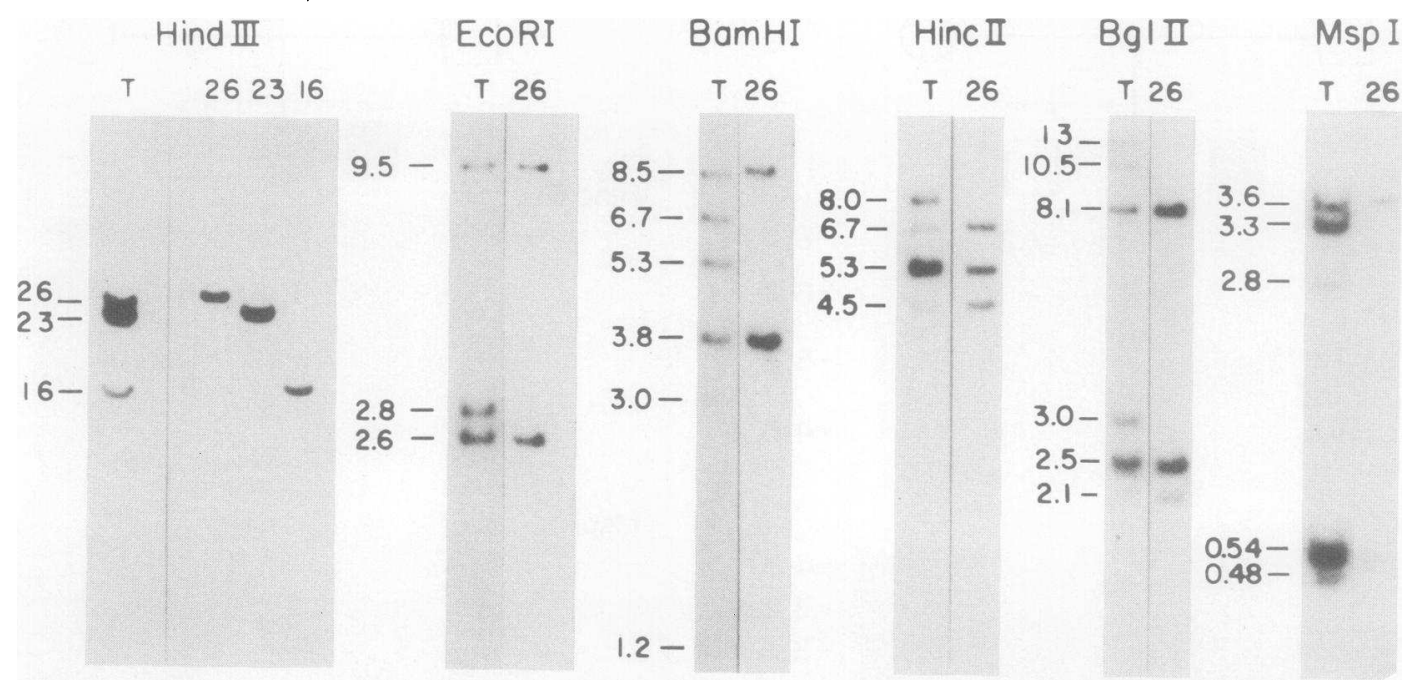

Figure 3 Autoradiogram patterns of total DNA from a normal control (T) and the 26-, 23-, and 16-kb fractions isolated following HindIII restriction endonuclease digestion and hybridization to the hGH probe. Patterns seen following digestion of aliquots of total DNA (T) and the 26-kb fraction " 26 " with EcoRI (lanes 5,6) or BamHI (lanes 7, 8) demonstrate the 26kb fraction contains the hGH-N and GH-L genes (7). The patterns seen after HincII (lanes 9 , 10), BglII (lanes 11, 12), or MspI (lanes 13, 14) digestion indicate that the HincII $(6.7 / 4.5)$ and the $M s p I(4.3 / 3.6)$ polymorphic restriction sites are within the $26-\mathrm{kb}$ fraction and physically linked to the hGH-N gene.

hCS genes are contained in the 23- and 16-kb fragments (data not shown).

The polymorphic restriction sites, which yield $6.7 /$ 4.5-kb fragments after HincII digestion and 4.3/3.6$\mathrm{kb}$ fragments after $M s p I$ digestion, are within the 26kb HindIII fragment and are thus physically linked to the hGH-N locus (Fig. 3). The 23- and 16-kb HindIII fragments contain the hCS and hGH-V loci and the three remaining polymorphic restriction sites.

The exact location of the polymorphic HincII site was determined by comparison of EcoRI plus HincII digests of DNA from individuals who are homozygous for the presence or absence of the HincII polymorphic site $(4.5 / 4.5$ or $6.7 / 6.7)$. The $2.6-\mathrm{kb}$ EcoRI fragment, which contains the hGH-N gene, is cut to $2.15 \mathrm{~kb}$ in DNA from the 4.5/4.5 homozygotes but not in DNA from 6.7/6.7 homozygotes, indicating that the HincII site is $\sim 0.45 \mathrm{~kb}$ from an EcoRI site flanking the gene (data not shown). Sequencing data of a cloned hGH$\mathrm{N}$ gene $(\lambda \mathrm{hGH}-\mathrm{N})$ further localizes the polymorphic HincII site 116 bp $5^{\prime}$ to the -26 codon hGH-N. ${ }^{2}$ This site is not present in the hGH-N allele sequenced by DeNoto et al. (22).

Results obtained after MspI or EcoRI plus MspI digestion of the 26-kb HindIII generated fragment indicated that the polymorphic $M s p I$ site, which yields 4.3/3.6-kb fragments, is adjacent to the GH-L gene.

\footnotetext{
${ }^{2}$ Seeburg, P. H. Unpublished observations.
}

Since a genomic clone with an insert size of $\sim 17 \mathrm{~kb}$ has been described, which contains both the GH-L and the hGH-N genes (5), we calculate that the 4.3/3.6-kb polymorphic $\mathrm{MspI}$ site is at most $17 \mathrm{~kb}$ from the far end of the hGH-N gene.

Pedigree and linkage analysis. The pedigrees of the nine families with IGHD I whose DNA were studied are shown in Fig. 4. Although all of these pedigrees are compatible with an autosomal recessive mode of inheritance, families A-D and I could also agree with an X-linked mode of inheritance. The hypogammaglobulinemia associated with the X-linked type of IGHD was excluded in affected males in families $C$ and D by IgG, IgA, and IgM quantitation.

For each polymorphic restriction site we used in linkage analysis the large fragments occur in the absence of $(-)$ and the small fragments in the presence of $(+)$ the polymorphic restriction site. Thus, the fragments resulting from the absence of $(-)$ or presence of $(+)$ the various polymorphic restriction sites were designated as follows: HincII $(-6.7,+4.5), M s p I$ (A: $-4.3,+3.6$; B: $-3.9,+3.3)$, and $B g l \mathrm{II}(\mathrm{A}:-13,+10.5$; B: $-8.1,+3.0)$. In Fig. I the autoradiogram patterns of DNA from family C Fig. 4 are shown. Note that the father has the following patterns: HincII (4.5/4.5 $=+/+$ ), MspI (A: 3.6/3.6 = +/+; B: $3.3 / 3.3=+$ / + ), and BglII (A: $13 / 13=-/-$ ). Thus, he is homozygous for +++- haplotypes that are separated by a vertical line below his pedigree symbol (see family $\mathrm{C}$, 

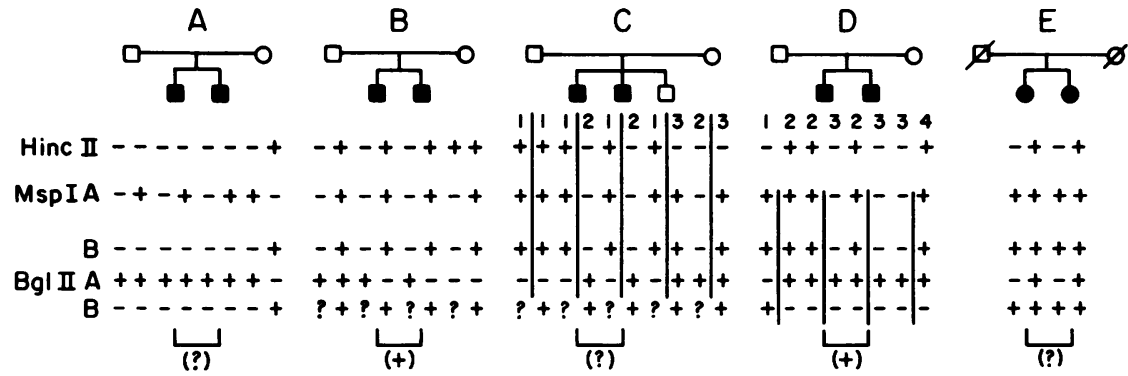

$F$

G
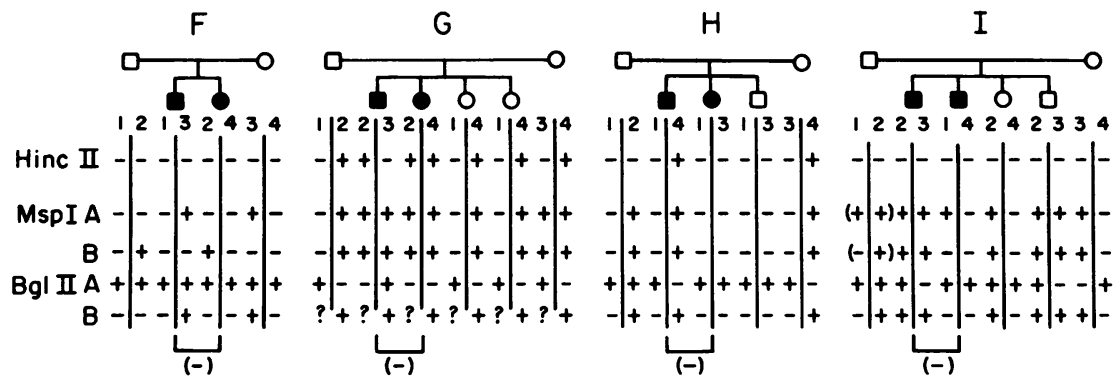

Figure 4 Pedigrees of nine families each of which has two sibs (solid symbols) affected with IGHD I. Below each individual's pedigree symbol the absence $(-)$ or presence $(+)$ of polymorphic restriction sites for $\mathrm{HincII}(-6.7,+4.5), \mathrm{MspI}(\mathrm{A}:-4.3,+3.6 ; \mathrm{B}:-3.9,+3.3)$ or $\mathrm{BglII}$ $(\mathrm{A}:-13,+10.5 ; \mathrm{B}:-8.1,+3.0)$ are shown. Where the coupling phases of the different sites could be established (see text) the haplotypes of homologous chromosomes are separated by a vertical line. Symbols below the small brackets indicate whether affected sib pairs have concordant $(+)$, possibly concordant (?) or discordant $(-)$ patterns or haplotypes.

Fig. 4). The mother in this family has the following patterns: HincII $(6.7 / 6.7=-/-)$, MspI (A: 4.3/3.6 $=-/+;$ B: $3.9 / 3.3=-/+$ ) and BglII (A: $10.5 / 10.5$ $=+/+)$. Given the haplotypes of her husband $(+++-/+++-)$ and two affected sons (+++-/ $--+)$, it can be deduced that her haplotypes are ---+ and -+++ . If her husband's identical haplotypes $(+++-)$ are designated as haplotype 1 and her haplotypes as $2(---+)$ and $3(-+++)$, respectively, it can be seen that both affected sons have inherited haplotyes 1 and 2. At first it would appear these affected sibs have concordant haplotypes but since their father's two haplotypes are indistinguishable, it remains possible that they inherited alternative paternal haplotypes. Thus, they are only possibly concordant as indicated by a (?) below the bracket connecting their haplotypes. A second example is shown in Fig. 2 , which corresponds to family $\mathrm{H}$ in Fig. 4. By analysis of Fig. 2 it can be seen that the affected sibs have discordant patterns after HincII, MspI, or BglII digestion. The presence of a child with homozygosity for the ---+- haplotype enables the complete assignment of parental haplotypes. The father has ---+- and -++++ haplotypes, designated 1 and 2 , and the mother has - - + - and +++-+ haplotypes, designated 3 and 4 . It can then be seen that the two affected sibs are discordant because one inherited haplotypes 1 and 4 while the other inherited haplotyes 1 and 3 . This discordance is indicated by a $(-)$ beneath the bracket that connects their haplotypes. In families $\mathrm{A}, \mathrm{B}$, and $\mathrm{E}$ the polymorphism patterns were not sufficiently informative to allow the determination of coupling phases; nevertheless, it was possible to prove concordance for maternal and paternal alleles in family $B$. In the remaining families $(D, F-I)$, where the complete or partial haplotypes of the homologous chromosomes could be determined, the haplotypes are separated by vertical lines. No evidence of recombination between the various polymorphic restriction sites was found in any pedigree.

\section{DISCUSSION}

Among the nine pairs of sibs affected with IGHD I shown in Fig. 4, those in families F-I were discordant for different polymorphic restriction sites inherited from their parents. Since two of these sites (HincII and $M s p I$ A) are shown to be very close to the structural gene for hGH (hGH-N) we conclude the affected sibs in families F-I have inherited different hGH-N alleles. Different maternal alleles were inherited by affected sibs in families $G$ and $H$ while in families $F$ and $I$ different maternal as well as paternal alleles were inherited. This discordance could arise from meiotic 
chromosomal recombination(s) between the hGH-N allele and the adjacent polymorphic restriction sites of one or both parents. The probability of meiotic recombination as an explanation for this discordance is roughly equal to the distance in bp between the allele and site in question, divided by $10^{8}$ bp (23). For the Hincll site, which is $116 \mathrm{bp}$ from the -26 codon, and $2.2 \mathrm{~kb}$ from the poly A addition site of $\mathrm{hGH}-\mathrm{N},{ }^{2}$ the probability is $2.2 \times 10^{3} / 10^{8}$ or $\sim 1$ in 45,500 per generation. For the $M s p I$ A site $(4.3 / 3.6)$, which is no more than $17 \times 10^{3} \mathrm{bp}$ from the hGH-N gene, the probability is $\sim 1$ in 5,900 per generation. A more likely explanation for this discordance between the disease state and the polymorphic restriction sites inherited by these sib pairs is that the mutation causing the IGHD I phenotype and the hGH-N structural gene assort independently. This implies that the mutation involved in IGHD I affects a gene responsible for development or regulation of somatotrophic cell function rather than the hGH-N structural gene.

In the remaining five families (Figs. 1 and 3, A-E), the affected sib pairs would at first appear to have concordant hGH-N genotypes. However, concordance [indicated by a $(+)$ below the bracket connecting their haplotype] is firmly established only for sib pairs $B$ and D. In families A, C, and E discordance remains possible [indicated by a (?) below the brackets connecting their haplotypes] because the markers are not sufficiently informative to prove concordance.

Among the nine affected sib pairs, two were definitely concordant, three were possibly concordant, and four were definitely discordant for polymorphic restriction site haplotypes. These results indicate that a large fraction of cases of IGHD I are due to alterations not linked to the hGH-N gene. The concordant cases may reflect the expected $25 \%$ occurrence of concordance for independently assorting characteristics or they may reflect heterogeneity in the genetic basis of IGHD I with a subset of cases being due to an alteration in the hGH-N gene.

Recently Orkin et al. have shown that specific mutations causing $\beta$-thalassemia are often associated with specific polymorphic restriction site haplotypes (24). Using this analogy, if the defect causing IGHD I in families $C$ and $D$ were in or near the hGH-N gene, one might expect the mutation to be associated with a specific haplotype. In fact, the affected sibs in families $C$ and D have at least three different haplotypes.

Our experience suggests a need for caution in the use of restriction site polymorphisms for diagnosis and prediction of inherited diseases. Such use should be predicated upon study of a sufficient number of families to establish linkage and homogeneity of the disease. For example, conclusions based upon definite or possible concordance between restriction patterns and disease in families A-E would have led to erroneous predictions of the absence of disease in the second affected siblings in families F-I.

Analysis of polymorphic restriction patterns provides a powerful approach for establishing the absence of linkage between a particular disease and a particular gene within a single family. Using a relatively rapid and inexpensive technique, we determined that hGH-N gene sequencing would not succeed in establishing the molecular basis of IGHD I in at least four of the nine families studied. In these families, any sequence changes that might be found would probably be irrelevant to their disease. Within the spectrum of disorders involving growth, this approach will be particularly valuable in identifying those children suspected of having biologically inactive hGH (25) whose DNA would be appropriate for cloning and sequencing of the hGH-N gene.

Note added in proof. Since submission of this manuscript we have studied samples provided by Drs. J. Bailey, L. Kirby, C. Sultan, and J. Tze from three additional IGHD I families. In each of these additional families the affected sib pairs were discordant for polymorphic restriction site haplotypes. Thus, in at least 7 of 12 IGHD I families the basic defect is not linked to the hGH-N gene.

\section{ACKNOWLEDGMENTS}

The authors thank Ms. Sandy Muscelli for her expert assistance in preparing the manuscript. We also thank Drs. Robert Blizzard, Thaddeus Kelly, Paul Malvaux, and Milo Zachmann for providing clinical samples and Linda Vinson for technical assistance.

This work was supported in part by National Institutes of Health grants AM 00423, AM 28246, AM 00005, RR00240, RR05506; a Denison Award and a March of Dimes Birth Defects Foundation clinical research grant 6-309.

\section{REFERENCES}

1. Niall, H. D., M. L. Hogan, R. Sauer, I. .Y. Rosenblum, and F. C. Greenwood. 1971. Sequences of pituitary and placental lactogenic and growth hormones: evolution from a primordial peptide by gene reduplication. Proc. Natl. Acad. Sci. U. S. A. 68: 866-870.

2. Fiddes, J. C., P. H. Seeburg, F. M. DeNoto, R. A. Hallewell, J. D. Baxter, and H. M. Goodman. 1979. Structure of genes for human growth hormone and chorionic somatomammotropin. Proc. Natl. Acad. Sci. U. S. A. 76: 4294-4298.

3. Owerbach, D., W. J. Rutter, J. A. Martial, J. D. Baxter, and T. B. Shows. 1980. Genes for growth hormone, chorionic somatomammotropin, and growth hormone-like gene on chromosome 17 in humans. Science (Wash. DC). 209: 289-292.

4. George, D. L., J. A. Phillips, III, U. Francke, and P. H. Seeburg. 1981. The genes for growth hormone and chorionic somatomammotropin are on the long arm of human chromosome 17 in region q $21 \rightarrow$ qter. Hum. Genet. 57: 138-141.

5. Goodman, H. M., F. DeNoto, J. C. Fiddes, R. A. Hal- 
lewell, G. S. Page, S. Smith, and E. Tischer. 1980. Structure and evolution of growth hormone related genes. In Mobilization and Reassembly of Genetic Information. Miami Winter Symposium. W. A. Scott, R. Werner, D. R. Joseph, and J. Schultz, editors. Academic Press, Inc. New York. 17: 155-179.

6. Seeburg, P. H. 1980. Structure and regulation of pituitary hormone genes. In Polypeptide Hormones. R. F. Beers and E. G. Bassett, editors. Raven Press, New York. 19-31.

7. Phillips, J. A., III, B. L. Hjelle, P. H. Seeburg, and M. Zachmann. 1981. Molecular basis for familial isolated growth hormone deficiency. Proc. Natl. Acad. Sci. U. S. A. 78: 6372-6375.

8. Pavlakis, G. N., N. Hizuka, P. Gorden, P. H. Seeburg, and D. H. Hamer. 1981. Expression of two human growth hormone genes in monkey cells infected by simian virus 40 recombinants. Proc. Natl. Acad. Sci. U. S. A. 78: 7398-7402.

9. Underwood, L. E., and J. J. Van Wyk. 1981. Hormones in normal and aberrant growth. In Textbook of Endocrinology. R. H. Williams, editor. W. B. Saunders, Company, Philadelphia. 1149-1191.

10. Rimoin, D. L. 1976. Hereditary forms of growth hormone deficiency and resistance. Birth Defects. 12: 1529.

11. Fleisher, T. A., R. M. White, S. Broder, S. P. Nissley, R. M. Blaese, J. J. Mulvihill, G. Olive, and T. A. Waldmann. 1980. X-linked hypogammoglobulinemia and isolated growth hormone deficiency. N. Engl. J. Med. 302: 1429-1434.

12. Rimoin, D. L., and J. E. Schechter. 1973. Histological and ultrastructural studies in isolated growth hormone deficiency. J. Clin. Endocrinol. 37: 725-735.

13. Maniatis, T., E. F. Fritsch, J. Lauer, and R. M. Lawn. 1980. The molecular genetics of human hemoglobins. Annu. Rev. Genet. 14: 145-178.

14. Kunkel, L. M., K. D. Smith, S. H. Boyer, D. S. Borgaonkor, S. S. Wachtel, O. J. Miller, W. R. Breg, H. W. Jones, and J. M. Rary. 1977. Analysis of human Y-chromosome specific reiterated DNA in chromosome variants. Proc. Natl. Acad. Sci. U. S. A. 74: 1245-1249.
15. Martial, J. A., R. A. Hallewell, J. D. Baxter, and H. M. Goodman. 1979. Human growth hormone: complementary DNA cloning and expression in bacteria. Science (Wash. DC). 205: 602-607.

16. Vogelstein, B., and D. Gillespie. 1979. Preparative and analytical purification of DNA from agarose. Proc. Natl. Acad. Sci. U. S. A. 76: 615-619.

17. Maniatis, T., G. S. Kee, A. Efstratiadis, and F. C. Kafatos. 1976. Amplification and characterization of a $\beta$-globin gene synthesized in vitro. Cell. 8: 163-182.

18. Shine, J., P. H. Seeburg, J. A. Martial, J. D. Baxter, and H. M. Goodman. 1977. Construction and analysis of recombinant DNA for human chorionic somatomammotropin. Nature (Lond.). 270: 494-499.

19. McDonell, M. W., M. N. Simon, and F. W. Studier. 1977. Analysis of restriction fragments of T7 DNA and determination of molecular weights by electrophoresis in neutral and alkaline gels. J. Mol. Biol. 110: 119-146.

20. Southern, E. M. 1975. Detection of specific sequences among DNA fragments separated by gel electrophoresis. J. Mol. Biol. 98: 503-517.

21. Jeffreys, A. J., and R. A. Flavell. 1977. A physical map of the DNA regions flanking the rabbit $\beta$-globin gene. Cell. 12: 429-439.

22. DeNoto, F. M., D. D. Moore, and H. M. Goodman. 1981. Human growth hormone DNA sequence and mRNA structure: possible alternative splicing. Nucleic Acids Res. 9: 3719-3730.

23. Kurnit, D. M., and H. Hoehn. 1979. Prenatal diagnosis of human genome variation. Annu. Rev. Genet. 13: 235258.

24. Orkin, S. H., H. H. Kazazian, Jr., S. E. Antonarakis, S. C. Goff, C. D. Boehm, J. P. Sexton, P. G. Waber, and J. V. Giardinia. 1982. $\beta$-Thalassemia mutations, $\beta$-globin gene polymorphisms, and their linkage with DNA polymorphisms in the human $\beta$-globin gene cluster. Nature (Lond.). 296: 627-631.

25. Kowarski, A. A., J. Schneider, E. Ben-Galim, V. V. Weldon, and W. H. Daughaday. 1978. Growth failure with normal serum RIA-GH and low somatomedin activity: somatomedin restoration and growth acceleration after exogenous GH. J. Clin. Endocrinol. Metab. 47: 461-464. 